\title{
INVENTARISASI JARINGAN PIPA PDAM KABUPATEN SITUBONDO DENGAN MEMANFAATKAN SISTEM INFORMASI GEORAFIS (SIG)
}

\author{
Muhammad Taufik, Ginta Widya Seftiara, Akbar Kurniawan \\ Departemen Teknik Geomatika, FTSLK-ITS, Kampus ITS Sukolilo, Surabaya, 60111, Indonesia \\ e-mail : taufik_m@geodesy.its.ac.id, gintaws@gmail.com, akbar.geodesy@gmail.com
}

\begin{abstract}
Abstrak
PDAM Tirta Baluran di Kabupaten Situbondo, dalam rangka meningkatkan kinerja pelayanan, perlu merencanakan pengembangan jaringan distribusi yang menjamin ketersediaan air secara menerus. Dari sisi pelaksanaan di lapangan, informasi dan data akan kondisi sistem jaringan distribusi; sangat diperlukan juga untuk pengelolaan aset. Pengelolaan aset bagi PDAM Tirta Baluran merupakan upaya manajamen jaringan pipa dalam lingkup PDAM yang tidak dapat dikelola secara konvensional. Pemanfaatan Sistem Informasi Geografis menggunakan perangkat lunak Visual Basic merupakan teknologi yang dimanfaatkan untuk inventarisasi terhadap jaringan pipa yang ada di Kabupaten Situbondo dan dapat dikembangkan sebagai alat untuk manajemen dan pembangunan PDAM. Berdasarkan hasil penelitian, saat ini PDAMA Tirta Baluran memiliki jaringan pipa primer mempunyai panjang 18,177 km dan pipa sekunder sepanjang $18,0432 \mathrm{~km}$. Jaringan pipa tersebut hanya ada di (3) tiga wilayah kecamatan yaitu Kecamatan Situbondo, Kecamatan Panji, dan Kecamatan Panarukan.
\end{abstract}

Kata Kunci- PDAM, Jaringan pipa , Sistem Informasi Geografis, Visual Basic

\begin{abstract}
The PDAM Tirta Baluran in Situbondo Regency, in order to improve the service performance, requies the development of a distribution network to ensures that water suply continuously. The implementation of field requaries data and information about the condition of network distribution system water supply; where is also necessary for asset management. The Asset management of PDAM Tirta Baluran base on the effort of pipeline management that can not be managed conventionally. Geographic Information System using Visual Basic software is a technology used for the inventory of these primary and secondary pipelines of PDAM on the Situbondo Regency and developed as a tool for management, monitoring, and development. The Results of this study, the PDAM Tira Baluran has currently the primary pipelimes totally $18.177 \mathrm{~km}$ of length and $18.0432 \mathrm{~km}$ length of the secondary pipelines. These pipelines are available only in (3) three districts of Situbondo, Panji and Panaruka
\end{abstract}

Keywords-PDAM, pipelines, Geographic Information Syatems, Visual Basic

\section{PENDAHULUAN}

PDAM atau perusahaan daerah air minum merupakan salah satu unit usaha milik daerah yang bergerak dalam distribusi air bersih bagi masyarakat umum yang diawasi dan dimonitor oleh aparat-aparat eksekutif maupun legislatif. PDAM terdapat di setiap provinsi, kabupaten, dan kotamadya di seluruh Indonesia. Keputusan tersebut berdasarkan Peraturan Pemerintah No. 14 tahun 1987 tentang Penyerahan Sebagian Urusan Pemerintah Di Bidang Pekerjaan Umum Kepada Daerah, menyatakan bahwa tanggung jawab dalam menyediakan supply air bersih yakni pemerintah daerah.
PDAM Tirta Baluran berlokasi di Kabupaten Situbondo, merupakan perusahaan air minum di yang berdiri sejak pemerintahan Hindia Belanda (VOC) pada tahun 1936. Hingga saat ini, PDAM ini terus berupaya memenuhi kebutuhan air bersih dengan meningkatkan kinerja pelayanan kepada seluruh pelanggan baik dalam meningkatkan kualitas air, menambah jumlah kapasitas produksi maupun melakukan perbaikan sistem jaringan distribusi yang ada di Kabupaten Situbondo.

Dalam melakukan pelayanan kepada masyarakat, sistem jaringan distribusi air minum merupakan 
bagian yang sangat penting dari suatu kesatuan sistem penyediaan air bersih. Sistem distribusi adalah jaringan perpipaan untuk mengalirkan air minum dari reservoir menuju daerah pelayanan atau konsumen. Fungsi pokok dari jaringan pipa distribusi adalah untuk menghantarkan air bersih kepada seluruh pelanggan dengan tetap memperhatikan faktor kualitas, kuantitas dan tekanan air. Sementara itu, kondisi yang diinginkan oleh seluruh pelanggan adalah ketersediaan air secara terus menerus. Sebelum pelaksanaan operasional kegiatan, PDAM Tirta Baluran harus mengetahui kondisi pada sistem jaringan distribusi terlebih dahulu.

Sistem Informasi Geografis (SIG) sudah lama dikenal di masyarakat sebagai perangkat yang dapat membantu kebutuhan bagi beberapa perusahaan dalam rangka membantu persoaalan dan pengembangan perusahaan. SIG mempunyai kemampuan untuk menghubungkan berbagai informasi yang dikaitkan dengan posisi geografis atau lokasi yang terdapat di sekitar kehidupan manusia di bumi. Pemanfaat teknologi SIG ini akan sangat membantu manajemen PDAM Tirta Baluran dalam rangka pengelolaan aset mulai dari perencanaan kebutuhan, penyediaan dana, pengoperasian, pemeliharaan, dan penambahan aset, dalam rangka meningkatkan peleyanan distribusi air bersih bagi masyarakat di Kabupaten Situbondo.

Penelitian mengenai inventarisasi aset jaringan distribusi pipa pernah dilakukan oleh Michel Frans (2005). Dalam penelitian tersebut melakukan inventarisasi pipa primer dan sekunder PDAM Surabaya, khususnya Kelurahan Kedung Baruk pada Kecamatan Rungkut deengan menggunakan perangkat lunak SIG. Dengan pemanfatan Sistem Informasi Geografis (SIG) diharapkan dapat digunakan sebagai alat analisa untuk mengelola dan mengembangkan aset jaringan pipa PDAM Tirta Baluran Kabupaten Situbondo agar menjadi lebih efisien dan efektif.

\section{METODOLOGI PENELITIAN}

Lokasi penelitian ini terletaki di Kabupaten Situbondo dengan posisi geografis $7^{\circ} 35^{\prime}-7^{\circ} 44^{\prime}$ Lintang Selatan dan $113^{\circ} 30^{\prime}-114^{\circ} 42^{\prime}$ Bujur Timur, dengan di bagian sebelah utara dibatasi oleh Selat Madura, di bagian timur berbatasan dengan Selat Bali, di bagian Selatan berbatasan dengan kabupaten Bondowoso dan kabupaten Banyuwangi di bagian barat berbatasan dengan kabupaten Probolinggo.

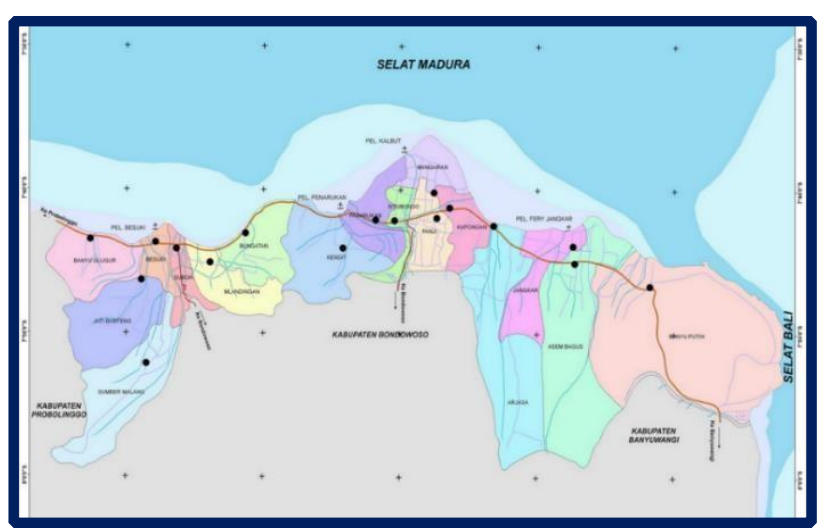

Gambar 1. Lokasi Penelitian

Luas wilayah administratif Kabupaten Situbondo mencapai $1.638,5 \mathrm{Km}^{2}$ yang terdiri dari 132 Desa dan 4 Kelurahan yang tersebar di 17 Kecamatan. Dari hasil sensus penduduk tahun 2010, jumlah penduduk Kabupaten Situbondo berdasarkan data sensus penduduk tahun 2010 sebanyak 647.619 jiwa. Sedangkan berdasarkan hasil sensus penduduk tahun 2015, jumlah penduduk Kabupaten Situbondo sebanyak 669.713 jiwa yang terdiri dari 326.500 penduduk laki-laki dan 343.213 penduduk perempuan.

Dalam penelitian ini, data yang digunakan jaringan pipa berupa yang berupa gambar denah dari jaringan pipa yang ada di PDAM kabupaten Situbondo, dan data tabular. Pengolahan data dilakukan dengan teknologi Sistem Informasi Geografis dengan metode overlay union, dan tampilan Visual Basic.

\section{HASIL DAN PEMBAHASAN}

Pembangunan database jaringan pipa PDAM Dengan proses digitasi denah jaringan pipa PDAM dibangun database jaringan pipa PDAM dengan cara membedakan pipa primer dan sekunder yang dilengkapi dengan informasi jenis dan diameter pipa. Kemudian dengan menggunakan citra satelit yang telah koreksi kemudian dilakukan proses tumpang susun terhadap peta garis yang ada layer jalan dan batas kecamatan. Posisi dari jaringan pipa PDAM setelah dilakukan verifikasi menjadi jaringan pipa PDAM yang ada di kabupaten Situbondo. 


\section{Data Spasial}

Data spasial yang dijadikan untuk Sistem Informasi Geografis Jaringan Pipa PDAM terdiri dari beberapa layer, antara lain Layer batas kabupaten ,Layer batas kecamatan, Layer batas desa, Layer jalan, Layer sungai, Layer bangunan dan Layer jalur pipa

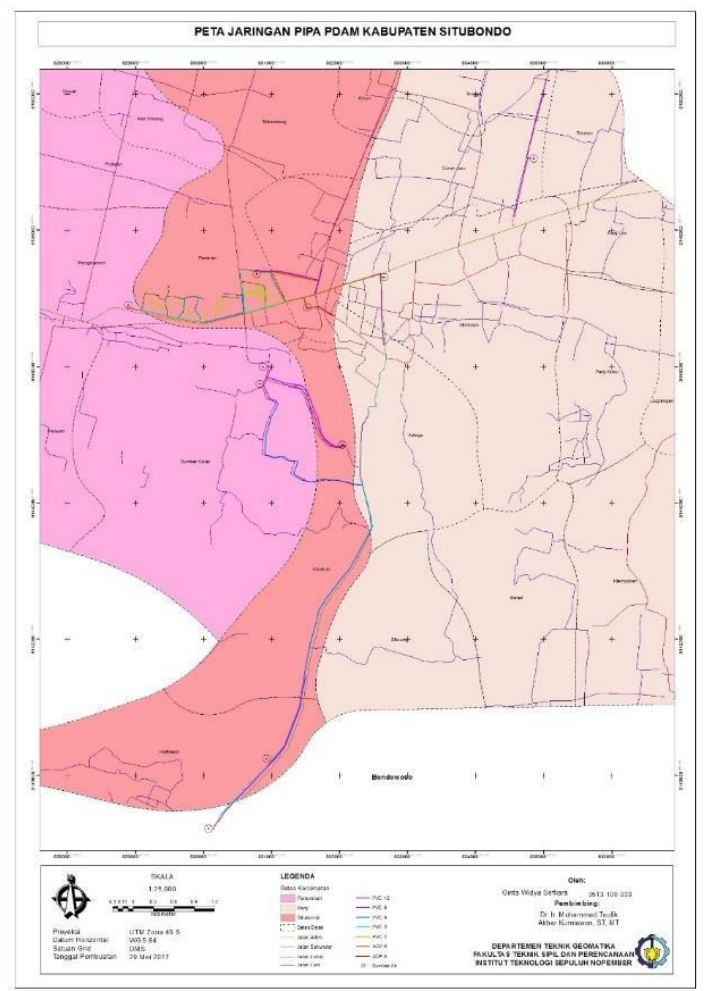

Gambar 2. Peta Jaringan Pipa Eksisting di PDAM Tirta Baluran Kabupaten Situbondo

\section{Data non spasial}

Pengolahan data non-spasial dilakukan dengan proses memasukkan atribut Jaringan pipa distribusi minum di PDAM PDAM Tirta Baluran Kabupaten Situbondo .

Tabel 1. Peta Jaringan Pipa Eksisting di PDAM Tirta Baluran Kabupaten Situbondo

\begin{tabular}{ccccc}
\hline Pipa & Bahan & Diameter & Panjang & $\begin{array}{c}\text { Jumlah } \\
\text { jalur }\end{array}$ \\
\hline Primer & ACP & 6 inch & $0,7 \mathrm{~km}$ & 4 \\
& ACP & 8 inch & $5,9 \mathrm{~km}$ & 16 \\
& PVC & 6 inch & $11,2 \mathrm{~km}$ & 74 \\
& PVC & 12 inch & $1,0 \mathrm{~km}$ & 7 \\
Sekunder & PVC & 2 inch & $5,1 \mathrm{~km}$ & 65 \\
& PVC & 3 inch & $5,0 \mathrm{~km}$ & 29 \\
& PVC & 4 inch & $11,2 \mathrm{~km}$ & 1 \\
\hline
\end{tabular}

Sumber: PDAM Tirta Baluran Kabupaten Situbondo

\section{Hasil inventarisasi}

Dari pengolahan data yang dilakukan didapatkan hasil berupa Peta Aset Jaringan Pipa PDAM Tirta Baluran kabupaten Situbondo, terdapat Jaringan pipa primer sepanjang 18,177 km yang terbagi dalam 101 jalur dan jaringan pipa sekunder dengan panjang 18,043 km yang terbagi dalam 153 jalur.

Jaringan pipa distribusi tersebut sementara terbatas di 3 wilayah Kecamatan saja, yaitu di Kecamatan Situbondo yang meliputi kelurahan Patokan, Dawuhan, Kotakan dan desa Kalibagor. Adapun selebihnya ada di Kecamatan Panji yang meliputi Kelurahan Mimbaan, Kelurahan Adirejo, Desa Curah Jeru, dan Desa Tenggir serta di Kecamatan Panarukan yang mencakup Desa Sumber Kolak, dan Desa Wringinanom

Sumur Mata Air PDAM

PDAM Tirta Baluran Kabupaten Situbondo mempunyai 12 sumber mata air bagi jaringan distribusi yang berupa sumur bor seperti pada tabel 2.

Tabel 2. Kapasitas Debit Setiap Sumur Bor

\begin{tabular}{|c|c|c|c|c|}
\hline No & Sumur Bor & $\begin{array}{c}\text { Kapasitas } \\
\text { Sumber } \\
\text { (l/dtk) }\end{array}$ & $\begin{array}{c}\text { Kapasitas } \\
\text { Terpasang } \\
\text { (l/dtk) }\end{array}$ & $\begin{array}{c}\text { Kapasitas } \\
\text { Produksi } \\
\text { (l/dtk) }\end{array}$ \\
\hline 1 & $\begin{array}{l}\text { Sumur Bor } \\
\text { Argopuro }\end{array}$ & 18 & 15 & 14 \\
\hline 2 & $\begin{array}{l}\text { Sumur Bor } \\
\text { Karang } \\
\text { Asem }\end{array}$ & 23 & 20 & 19,5 \\
\hline 3 & $\begin{array}{l}\text { Sumur Bor } \\
\text { Kartini }\end{array}$ & 23 & 21 & 20 \\
\hline 4 & $\begin{array}{l}\text { Sumur Bor } \\
\text { kenanga }\end{array}$ & 28 & 26 & 25 \\
\hline 5 & $\begin{array}{l}\text { Sumur Bor } \\
\text { Sumber } \\
\text { Kolak } 1\end{array}$ & 10 & 7 & 6 \\
\hline 6 & $\begin{array}{l}\text { Sumur Bor } \\
\text { Sumber } \\
\text { Kolak } 2\end{array}$ & 16 & 15,5 & 13,5 \\
\hline 7 & $\begin{array}{l}\text { Sumur Bor } \\
\text { Kalibagor } 1\end{array}$ & 14 & 13,5 & 10 \\
\hline 8 & $\begin{array}{l}\text { Sumur Bor } \\
\text { Kalibagor } 2\end{array}$ & 14 & 13,5 & 10 \\
\hline 9 & $\begin{array}{l}\text { Sumur Bor } \\
\text { Panji }\end{array}$ & 20 & 19 & 17 \\
\hline 10 & $\begin{array}{l}\text { Sumur Bor } \\
\text { Anggrek }\end{array}$ & 22 & 20 & 17 \\
\hline 11 & $\begin{array}{l}\text { Sumur Bor } \\
\text { Kharisma }\end{array}$ & 24 & 22 & 20 \\
\hline 12 & $\begin{array}{l}\text { Sumur Bor } \\
\text { Bawean }\end{array}$ & 23 & 22 & 21 \\
\hline & Jumlah & 235 & 214,5 & 175 \\
\hline
\end{tabular}

Sumber:PDAM Tirta Baluran Kabupaten Situbondo 
Jaringan Pipa Distribusi

Pipa primer ACP 6 inch

Pipa ACP 6 bersumber dari Sumur Bor Argopuro yang berada di Jalan Argopuro kemudian disambungkan ke pipa ACP 8 di Jalan Basuki Rahmat. Selain itu Pipa ACP 6 juga berada di Jalan Diponegoro sebagai sambungan dari pipa ACP 8.

\section{Pipa primer ACP 8 inch}

Pipa ACP 8 bersumber dari Sumur Bor Karang Asem yang melewati Jalan PB Sudirman hingga Jalan Basuki Rahmat. Pipa ACP 8 juga bersumber dari Sumur Bor Kartini yang mana kemudian diteruskan dengan pipa ACP 6 inch di Jalan Diponegoro.

\section{Pipa Primer PVC 6 inch}

Pipa PVC 6 bersumber dari Sumur Bor kenanga yang meliputi Jalan kenanga - Jalan Wijaya Kusuma - Jalan Sucipto, hingga batas area pelayanan Desa Peleyan. Pipa PVC juga bersumber dari Sumur Bor Sumber Kolak yang berada pada Jalan Balura kemudian diteruskan ke Jalan Tembus baru dan Jalan Tembus Lama dengan pipa PVC 4. Sumber pipa PVC 6 juga berasal dari Sumur Bor Kalibagor 2 di Jalan Raya Situbondo.

Pipa Primer PVC 12 inch

Pipa PVC 12 bersumber dari Sumur Bor Argopuro yang berada di Jalan Argopuro.

Pipa Sekunder PVC 2 inch

Pipa PVC 2 merupakan sambungan dari pipa PVC 3 di Jalan PB Sudirman - Gang Lumbung. Pipa PVC 2 juga merupakan sambungan dari pipa PVC 4 berada di Jalan PB Sudirman - Jalan Wr. Supratman - Jalan Kenanga - Jalan Seroja. PVC juga berada di Jalan Mawar sebagai pipa sambungan dari pipa PVC 3

\section{Pipa Sekunder PVC 3 inch}

Pipa PVC 3 Merupakan sambungan pipa PVC 4 di Jalan PB Sudirman - Gang Setia - Gang Rahayu dan diteruskan dengan pipa PVC 2. Pipa PVC 3 juga merupakan sambungan dari pipa PVC 2 berada di Jalan PB Sudirman - Jalan Wr. Supratman - Jalan Kenanga - Jalan Seroja
Pipa Sekunder PVC 4 inch

Pipa PVC 4 berada di Jalan PB Sudirman merupakan sambungan dari pipa ACP 8 yang diteruskan kembali ke pipa PVC 3 di gang Setia dan pipa PVC 2 di Gang Anugrah. Pipa PVC 4 juga terdapat di Jalan Balura - Jalan Tembus Lama Jalan Raya Situbondo yang merupakan sambungan dari pipa PVC 6

Kepadatan penduduk

Jaringan pipa distribusi PDAM yang terdiri dari jaringan pipa primer dan pipa sekunder berada di daerah dengan tingkat kepadatan penduduk yang tinggi dan sedang. Berikut tabel kepadatan penduduk di Kabupaten Situbondo

Tabel 3. Kepadatan penduduk Kabupaten Situbondo

\begin{tabular}{ccc}
\hline Kecamatan & $\begin{array}{c}\text { Kepadatan } \\
\text { (Jiwa/ km²) }\end{array}$ & Keterangan \\
\hline $\begin{array}{c}\text { Sumbermalang } \\
\text { Jatibanteng }\end{array}$ & 204,08 & Rendah \\
Banyuglugur & 322,82 & Rendah \\
Besuki & 2428,89 & Rendah \\
Suboh & 875,94 & Tinggi \\
Mlandingan & 566,55 & Sedang \\
Bungatan & 380,76 & Rendah \\
Kendit & 249,96 & Rendah \\
Panarukan & 1026,65 & Sedang \\
Situbondo & 1723,27 & Tinggi \\
Mangaran & 700,62 & Rendah \\
Panji & 2013,28 & Tinggi \\
Kapongan & 857,96 & Rendah \\
Arjasa & 187,48 & Rendah \\
Jangkar & 552,69 & Rendah \\
Asembagus & 403,68 & Rendah \\
Banyuputih & 120,57 & Rendah \\
\hline Sumber : BPS Kabupaten Situbondo
\end{tabular}

Pipa primer dan sekunder PDAM Kabupaten Situbondo yang berlokasi di Kecamatan Panji, Situbondo, dan Panarukan. Keberadaan pipa tersebut didasari dengan tingginya tingkat kepadatan penduduk di tiga wilayah kecamatan. Dengan sebagaimana Kecamatan Panji dan Situbondo mempunyai tingkat kepadatan penduduk yang tinggi, serta Kecamatan Panarukan tingkat kepadatan penduduk yang sedang (BPS Situbondo, 2016).

Selain didasari dengan tingkat kependudukan yang tinggi, banyaknya pemukiman serta terletak di 
wilayah Pemerintahan Kabupaten Situbondo juga mendasari kebutuhan akan produksi air. Hal tersebut dapat dilihat pada gambar berikut

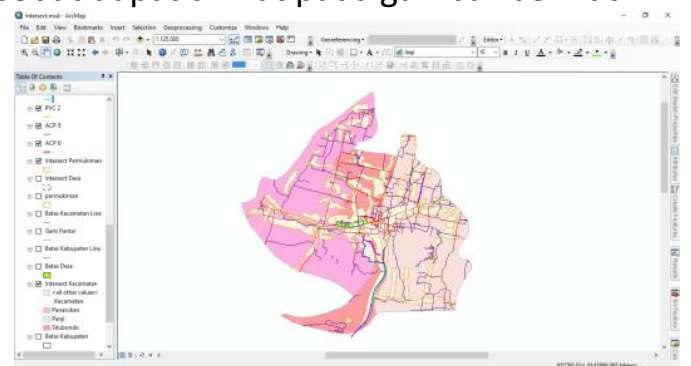

Gambar 3. Jaringan pipa distribusi priner dan sekunder PDAM berada di wilayah pemukiman

\section{KESIMPULAN}

Berdasarkan hasil penelitian yang telah dilakukan terdapat beberapa hal yang dapat disimpulkan dalam penelitian ini, yaitu :

1. PDAM Kabupaten Situbondo saat ini mempunyai 254 jalur jaringan distribusi dengan sumber air dari 12 sumur bor dengan kapasitas produksi 175 liter/detik; yang mencakup tiga wilayah kecamatan yaitu Kecamatan Situbondo, Kecamatan Panji, dan Kecamatan Panarukan dengan panjang $36,21949 \mathrm{~km}$. Jaringan pipa primer mempunyai panjang 18,177 km dan jaringan pipa sekunder dengan panjang 18,043 $\mathrm{km}$.

2. Sementara pelayanan Jaringan distribusi PDAM masih terbatas di wilayah yang memiliki tingkat kepadatan tinggi.

3. Aplikasi SIG, sudah saatnya digunakan oleh PDAM Tirta Bakuran untuk Perencanaan pengembangan jaringan pipa, penambahan kapasitas produksi, serta penggantian pipa yang telah berumur di atas 30 tahun dilakukan sebagai rencana evaluasi yang akan dilakukan oleh PDAM Kabupaten Situbondo

\section{DAFTAR PUSTAKA}

Badan Pusat Statistik Situbondo. 2016. Situbondo dalam angka 2015. Situbondo; BPS

Frans, M. 2005. Pembuatan Sistem Informasi Geografis (SIG) Untuk Inventarisasi Aset Jaringan Distribusi Pipa Primer dan Sekunder PDAM Surabaya (Studi Kasus : Kelurahan Kedung Baruk, Kecamatan Rungkut). Tugas Akhir. Surabaya: Jurusan Teknik Geomatika, Fakultas Teknik Sipil dan Perencanaan, Institut Teknologi Sepuluh Nopember

Keputusan Menteri Dalam Negeri No : 690-069 tahun 1992 tentang Pola Petunjuk Teknis Pengelolaan PDAM

Keputusan Menteri Dalam Negeri Nomor 47 Tahun 1999, tentang Pedoman Penilaian Kinerja PDAM

PDAM Tirta Baluran Kabupaten Situbondo. 2016. Corporate Plan PDAM Kabupaten Situbondo Periode 2017 - 2021. Situbondo

Peraturan Pemerintah No. 14 tahun 1987 tentang Penyerahan Sebagian Urusan Pemerintah Di Bidang Pekerjaan Umum Kepada Daerah 